\title{
Visual trends in the annual report: the case of Ericsson 1947-2016
}

Emelie Havemo

The self-archived postprint version of this journal article is available at Linköping University Institutional Repository (DiVA):

http://urn.kb.se/resolve?urn=urn:nbn:se:liu:diva-149264

N.B.: When citing this work, cite the original publication.

Havemo, E., (2018), Visual trends in the annual report: the case of Ericsson 1947-2016, Corporate Communications. An International Journal, 23(3), 312-325. https://doi.org/10.1108/CCIJ-03-20170015

Original publication available at:

https://doi.org/10.1108/CCIJ-03-2017-0015

Copyright: Emerald

http://www.emeraldinsight.com/ 


\title{
Visual trends in the annual report: the case of Ericsson 1947-2016
}

\author{
Emelie Havemo \\ Department of Management and Engineering, \\ Linköping University, Sweden \\ emelie.havemo@liu.se
}

\begin{abstract}
Purpose: Disclosure research has argued that visuals are increasingly used in annual reports as a way to increase the readability of the annual report, but comparatively little is known about diagrams compared to graphs and photographs. The purpose of this paper is to provide a historical account of visuals use in corporate disclosure, with an emphasis on diagrams, to show changes from the 1940s until present-day reporting.
\end{abstract}

Design/methodology/approach: Visual research methods were applied to analyze how diagrams, photographs and graphs were used in 69 annual reports of the Swedish telecom company Ericsson.

Findings: Photographs have been used with increasing frequency since the 1950s. Graph and diagram use has increased significantly since the 1990s while photograph use remained stable, suggesting that graphs and diagrams increasingly complement photographs for visually representing the organization in corporate disclosure. Factors explaining the case company's development include both internal (performance, individual preferences, shifting from a manufacturing-based strategy to a service-based strategy) and external (legislation, transformation of the telecom industry) aspects.

Originality/value: Visual elements in annual reports are increasingly oriented toward immaterial representations of the organization's standings and identity and diagrams are increasingly used and contribute to this. This finding motivates further research about diagram use in corporate communication, such as how different diagram types convey accounting messages, and whether diagrams serve as impression management devices. For regulators, it will be important to follow the emerging trend of diagram use, since it is becoming part of reporting practice.

Keywords: Annual report, Longitudinal, Telecom, Diagrams, Historical study, Visual accounting

Paper type: Research paper

This is the author's proof of an article in Corporate Communications: An International Journal, published by Emerald.

Please cite as:

Emelie Havemo, (2018) "Visual trends in the annual report: the case of Ericsson 1947-2016", Corporate Communications: An International Journal, Vol. 23 Issue: 3, pp. 312-325

Link to the published article: https://doi.org/10.1108/CCIJ-03-2017-0015 


\section{Introduction}

Visual content is increasingly used in corporate reporting (Beattie and Jones, 1997; Beattie et al., 2008; Ditlevsen, 2012b), as well as in society as a whole (Kress and van Leeuwen, 2006). The annual report is one of the most important corporate communication documents (Branco and Rodrigues, 2006), in which companies increasingly use different types of visuals, a development which has inspired studies investigating how visuals act as communicative resources to convey information (McKinstry, 1996; Preston et al., 1996; David, 2001; Ditlevsen, 2012a; Davison, 2014). For instance, visuals in the annual report can support communication about the corporate identity (McKinstry, 1996; Ditlevsen, 2012a), convey corporate values (De Groot et al., 2015), and improve intellectual capital reporting (Mouritsen et al., 2001). In addition, Beattie and Jones (1997) argue that using graphs can elevate annual reports from mere reporting to communication of information, while an experiment conducted by Karreman et al. (2014) found that cohesion between visuals and narratives was positively related to decisions to invest in a company. It follows that the visual elements included in the annual report can have consequences for how the company's past and future performance is perceived, and subsequently acted upon, by its stakeholders.

A type of visual that is often used in corporate communication is diagrams. Because diagrams visualize abstract concepts and their relationships (Kress and van Leeuwen, 2006), they can support communication about topics that are difficult to visualize, such as intellectual capital, strategic directions, and production processes. For instance, diagrams are included as best practice examples in a database with examples of successful integrated reporting practice (see for example examples.integratedreporting.org), and many firms include diagrams in their corporate communication on websites or in annual reports. However, although studies have addressed the increasingly visual style in this corporate communication document by investigating the use of photographs and graphs, a recent review of the visual accounting field revealed that few studies focused on the use of diagrams (Davison, 2015). An understanding of diagrams as communication resources is important for companies to better evaluate and design messages using diagrams, for scholars to describe and assess current developments in how accounting narratives are constructed with visuals, and for regulatory bodies to be able to make recommendations for diagram use that is in line with reporting guidelines.

Against this background, the purpose of this study is to provide a historical account of visuals use in corporate reporting, with an emphasis on diagrams, and thereby shed light on the role played by the hitherto neglected visual format of diagrams. Since diagrams are not the only visual element in annual reports, the approach of the study is to compare diagrams with the most commonly researched visual formats in corporate reporting, photographs and graphs, with the aim of contextualizing the role of diagrams based on concurrent developments in the visual communication style of the annual report as a whole.

The study is organized as follows. First, I provide a brief account of previous studies of visuals in annual reports, focusing specifically on longitudinal accounts as this is the approach I adopt in this study. Second, I use visual theory from semiotics to develop a framework of representative styles of visuals. Third, I outline the research design, the case context and the coding procedure. Next, I show how visuals are used in 69 annual reports from the Swedish telecom company Ericsson, focusing especially on diagrams. I conclude the paper with a summary of the findings and a discussion of limitations and potential directions for further research. 


\section{Related studies}

The trend of increasing frequency of visuals use in annual reports has inspired many studies to date. These studies frequently focus on photographs (Davison, 2015), and have shown that photographs can be used to portray key actors within the company, such as CEOs (Davison, 2010), employees (Anderson and Imperia, 1992), and customers (Dougherty and Kunda, 1990). Similarly, Campbell et al. (2009) explored the morality of representing faces in corporate communication. As for graphs, it has been suggested that graphs can make communication more effective (Beattie and Jones, 1997) as information is represented visually rather than narrated. However, graphs have also been shown to intentionally influence perceptions of performance through the distortion of scales or relationships (see e.g. Courtis, 1997; Beattie et al., 2008). Furthermore, in terms of diagrams, Davison's (2015) review of visual accounting research papers (not including papers on graph use) showed that only 3 out of 83 papers investigated diagrams or sketches. Of these, one focused on intellectual capital, one focused on the strategy map and one was a working paper about visualizing corporate governance and strategy. In other words, little is known about how diagrams are used in corporate reporting. In contrast to the limited research in the reporting literature, diagrams have been studied more extensively in other fields, for instance in semiotics (Kazmierczak, 2001; Kress and van Leeuwen, 2006), and cognition studies, where it has been argued that diagrams can facilitate problem-solving tasks (Larkin and Simon, 1987) and support distinctions between static and dynamic concepts (Heiser and Tversky, 2006). Therefore, in this study, I draw inspiration from these other fields, Kress and van Leeuwen's visual semiotics and cognitive studies, to develop a framework of diagrams as a communicative resource in corporate reporting.

With regard to changes in visuals use over time, there have been a few longitudinal studies, also focusing mainly on graphs (Beattie et al., 2008) and photographs (McKinstry, 1996). For instance, Beattie et al. (2008) conducted a cross-case comparison of graph use in the UK companies from the 1960 s through to the early 2000s and found that more graphs were used and that a larger share of companies used at least one graph by 2004. A study of Malaysian firms found similar patterns of increasing graph use over time (Abdul Rahman et al., 2014). As with several related studies (McKinstry, 1996; Bartlett and Jones, 1997; David, 2001; Ditlevsen, 2012b), Beattie et al. (2008) also found that the annual reports had become longer. They interpreted the combination of more visuals and a higher number of pages as evidence that the annual report increasingly served the purpose of a presentationdriven impression management tool (Beattie et al., 2008, p. 219).

A different approach previously used in longitudinal visual analyses of annual reports is case studies, which is the approach used in this study. One example is the longitudinal study of a UK fashion retailer's report (McKinstry, 1996), which used both quantitative and interpretive data to show that visuals use increased as a share of the total information in annual reports between 1930 and 1994 . The study also showed that the reports were increasingly used as a PR tool to communicate the firm's identity. For example, the front cover of the 1987 report showed a fashion model in a style similar to a fashion magazine, which was seen to project the identity of being a fashionable company through the choice of visual style. However, the study did not explore in depth how different types of visuals were used, instead providing examples of reporting fashions to indicate that the choice of visuals in the annual report was affected by both management wishes and market requirements.

In a more recent study of the Danish company Danisco's annual reports, Ditlevsen (2012b) used content analysis to distinguish between two main types of elements: analytical (e.g. graphs, tables) and representative (photos) images. The study indicates that the number of visual elements in the annual report grew steadily from none at all in the 1950 s to high levels in later years, particularly 
analytical visual formats such as graphs. While the study used a separation of visual types into two main categories (analytical and representative visuals) to conclude that Danisco's reports were more fact-oriented for using graphs and tables (analytical) rather than photos (representative visuals), Ditlevsen did not address the differences in use within each category, assuming instead that graphs and photos would always communicate information in the same way.

In conclusion, although previous studies have examined the use of visual expressions in annual reports, the understanding of how diagrams act as communicative resources in the corporate reporting context is limited. In order to develop an understanding of the role of diagrams in a reporting context, and thereby add to the field's grasp of how corporate messages are constructed with different visual elements, it is necessary to study what diagrams are used to illustrate, as well as how diagrams are used relative to other types of visuals; this is what the present study aims to do. The next chapter outlines the framework used to analyze and compare different types of visuals in annual reports.

\section{Theoretical framework of visuals in annual reports}

This study argues that the meaning of the annual report arises from the signs used in a particular communication setting (Kress and van Leeuwen, 2006), but that general tendencies can be described with concepts from semiotics. In this section, I therefore outline the terminology for describing how visual elements convey meaning by drawing on semiotics and visualization research. Although the emphasis in this study is on diagrams, it became clear during the research process that diagrams are not isolated elements within the annual report, instead they combine with other elements to convey information about the company's past, current and intended future performance. Therefore, to shed light on the role of diagrams in the annual report, I also show similarities and differences compared to other visual elements during the same time period, namely graphs and photographs. As I will argue below, these elements visualize the company either concretely or conceptually, and the difference can be linked to differences in the overall visual communication style of the annual report since the approaches rely on different types of organizational referents. Table 1 illustrates the analytical framework used to identify differences between concrete or conceptual diagrams, photographs and graphs. In the table, I also provide definitions and examples of diagrams, photographs, and graphs from Ericsson's annual reports.

[TABLE 1]

Diagrams visualize relationships between components, which supports communication about abstract ideas (Kazmierczak, 2001; Kress and van Leeuwen, 2006), through the use of spatial metaphors, i.e. the relative placement of objects in the diagram to indicate e.g. similarity, relative importance, or sequences (Tversky, 1997). A key feature of diagrams as communicative resources is that they represent either a concrete physical setting such as a map of a terrain, or a conceptual idea such as strategic logics (Falk et al., 2016); that is, they reference a physical reality (concrete maps) or an abstract idea (Meirelles, 2013). This distinction implies a difference in diagram use depending on how the representation relates to the referent of the annual report - the company's performance and identity. Thus, to compare diagrams with graphs and photographs, the specification of functions follows the same classification, i.e. whether these visuals represent a concrete or conceptual referent. 
This, in turn, helps to explain the role of diagrams in the annual report in relation to the company's overall visual approach.

In photographs, unlike in diagrams, the subject is a real event or landscape (Kazmierczak, 2001); however, the relevance of the photo to the accounting context does not depend solely on the subject, but also on the relationship between the referent and the representation. This relationship can be concrete, that is, showing an actual internal (e.g. employees, factories) or external (e.g. customers, installed products) reality (as-is), or it can be conceptual, that is, generic (the subject acts as an example), or purely symbolic, i.e. relying on conceptual (e.g. metaphorical) translation between the representation and the referent. Kress and van Leeuwen (2006) argue that photos can use visual devices such modality (degree of realism), perspective and framing to express meaning. As an example of this, David (2001) uses the case of an oil company's photo of an oil rig against a clear blue background that is used to represent the product. The photo relays an esthetic of simplicity and cleanliness, which is not realistically representative of oil production. Such depictions could be seen as an attempt to transform a symbolic representation of the company as a realistic representation to convey the identity of a sustainable company.

Finally, graphs use accepted visual formats that indicate relationships in quantitative data according to the relative size of elements and altitude of scales (Tversky, 1997). A graph can be said to represent the company as a concrete translation of numerical data, which means that graphs illustrate the numerically quantified reality. Graphs can convey both financial (e.g. earnings, sales) and non-financial (e.g. employee count) information (Beattie and Jones, 1997). In the analytical framework, concrete graphs are identified as those graphs relying on numerical data to reflect past or current performance, whereas conceptual graphs reflect an imagined or projected future state, or a non-numerical reality where the basis for translation is not numerical data.

\section{Research methodology}

As the purpose of this research is to provide an account of visuals use in annual reports, with an emphasis on diagrams, a longitudinal and single-case design was adopted. The intention of this design was to be able to capture changes in the visual style since the first use of visuals in Ericsson's annual reports (1947) and until the present day (2016). This historical design also aims to provide a deeper understanding of how the visual communication style at Ericsson has evolved in relation to both internal and external factors. A benefit of a longitudinal approach is that it allows for the study of reporting patterns over time (Campbell and Abdul Rahman, 2010), which allows this study to examine both the frequency of visual element use and how this has changed over time.

The analysis is based on the annual reports of the Swedish multinational telecom corporation Ericsson. Founded in Sweden in 1876 as a telegraph equipment repair shop, by the early 1900s, Telefonaktiebolaget LM Ericsson ("Ericsson") had expanded its operations to include the design and manufacturing of telephones, and was operating in several international markets, including Russia, Denmark and Mexico (Åsgård and Ellgren, 2000). In recent years, Ericsson, as per the industry norm (Li and Whalley, 2002), has undergone a shift from focusing on products and manufacturing to having a service-based value chain (Davies, 2004), and from analog to digital products (Ehrenkrona, 1998). This means that the company's history reflects many of the trends observable in society today, including globalization, servitization and digitization, which makes it an interesting and relevant company for capturing trends in visuals use in annual reports. 
The first stage of data analysis entailed counting the frequency of visual elements in Ericsson's annual reports. I followed the approach for content analysis proposed by Husin et al. (2012), whereby each visual element is counted as a single unit. A limitation of this approach is that it does not take into account the size of the visual elements, which is something that some studies have included as a parameter (e.g. McKinstry, 1996). The lack of such data means that a page containing four graphs would count more toward the number of visual elements than a full-page photograph. However, as each individual visual element could be seen to convey a separate message, there are grounds for counting them as serving a specific purpose regardless of size. To count visuals frequency, each annual report after 1947 (the first year of visuals use) was examined page-by-page, and each use of a visual element was recorded according to the principle of one count per visual element. Four codes were used to distinguish between types of elements: photographs, graphs, diagrams, and "other". "Other" includes sketches, visual reading cues such as a map placed at the beginning of a section about global operations, and composite visualizations where several photos or illustrations are combined into a single unit.

As a complement to the quantitative measure, I recorded a written account of each report's main theme and use of visuals, focusing on key representative characteristics of the visuals in a given year, such as what photos, diagrams and graphs showed, as well as changes in the content and visual style over the years. The written account was used to identify trends in the communication style, for example a change from using map diagrams to conceptual diagrams, and from using photos of employees, products, and factories, to using photos of customers and ideas. However, a downside to this qualitative description of the annual reports was that it was difficult to specify how these patterns had evolved over time. Thus, to better specify changes in the visual style, I expanded the coding from merely counting elements to also categorizing diagrams, photographs, and graphs according to the categories in Table I. I coded diagrams based on whether they referenced a concrete (maps) or conceptual (ideas) reality, as well as which topic was illustrated in the diagram. I also coded whether a diagram was re-used from a previous report, as re-using diagrams was a clear tendency in the material. To identify whether graphs were more concrete or conceptual, they were coded based on whether they showed current performance (concrete) or a prognosis of the future (conceptual), and whether they were based on numerical data (concrete) or ideas (conceptual).

As for the coding of photographs, I observed that the style of the photographs used in the report typically coincided with the theme depicted on the front page (61 out of 69 front-page visuals contained at least one photo). Therefore, to identify general patterns with regard to photograph use, I used the front page as a proxy for the photographic style. A downside to this approach is that using front pages limited the analysis to only the main dimension of photographic representation in a given year, which fails to take into account differences and tensions within a single report. However, I argue that the close links between inside photos and cover photos ensures that the approach captures the key photographic message of each report, thereby supporting the analysis of the chosen representative style of photos in Ericsson's annual reports. In addition, front pages have been used in previous studies to explain the general theme of an annual report (McKinstry, 1996; David, 2001; Davison, 2014), which suggests that front pages can act as an analytical proxy for a report's visualization approach.

Following Table 1, front pages were categorized according to their relationship with the organizational reality. This relationship was identified in the following way. Visuals showing internal things such as a factory, a product or technology were coded as internal as-is representations, and visuals showing external things, such as customers, the logo, or technology installed at a customer's site were coded as external as-is representations. Conversely, the conceptual codes of generic or symbolic 
representations were assigned to generic representations, such as a photo of a woman (as an example of a customer) working on a train (1992), and symbolic representations, such as the 2005 front page photo of children waving, which could be seen as symbolically linked to Ericsson's vision of being a communication enabler.

\section{Visual elements in Ericsson's annual reports over time}

In this section, I provide an overview of the development of visual elements in Ericsson's annual reports in order to describe diagram use in relation to the overall design approach of a report. The section that follows focuses specifically on how the diagrams reflect information about the company by relating to the general trend. Figure 1 illustrates the types of visual elements used in Ericsson's annual reports, as well as the total number of visual elements and number of pages. The line and bars indicate the number of visual elements in total (line) and divided into the four categories (bars): diagrams, graphs, photographs and "other". The shaded area corresponds to number of pages in the reports.

[FIGURE 1]

As indicated by Figure 1, the overall trend of visuals use in Ericsson's annual reports is that more visual elements are used ( 3 in 1947 and 117 in 2016), and that these are spread across a significantly higher number of pages (28 in 1947 and 188 in 2016). This is in line with previous studies finding that reports are generally longer and include more visual elements (e.g. McKinstry, 1996; Beattie et al., 2008; Ditlevsen, 2012b). However, Figure 1 also visualizes the general trend that the number of visuals increased in parallel with the number of pages until the 2000s, after which the reports became considerably longer. The number of visuals also increased but to a proportionately lower degree; one way to account for this is that longer financial notes sections were included from 2002 and onwards.

The 2002-2004 reports serve as noteworthy exceptions to the trend, as these reports are strikingly non-visual compared to previous and subsequent years. This exception coincides with a major strategic and financial crisis at Ericsson, e.g. due to a failure to adapt to new market trends. The non-visual narrative contains assurances of the company's prompt return to positive performance, which is comparable to McKinstry's (1996) finding that the UK fashion retailer's reporting became more somber in times of poor performance, with less extravagant color and design choices. Another example of a decrease in financial performance occurred in 2016, when the annual report's narrative sections stressed the company's savings program, the new CEO, and some visuals being used as future-oriented evidence of betterment through new strategic directions and cost-savings. However, despite the slight shift in narrative focus, the 2016 report included almost the same number of visuals (117, down from $124)$ as the previous year. The largest difference was that the number of graphs (32, down from 41 in 2015) was lower, with the 2016 report containing fewer graphs showing revenue and strategy. The lower number of graphs suggests selective (more minimalist) graph use to avoid disclosing worsening performance, since downward trends can be more easily observable when visualized. A partial response to Penrose's (2008) question of how negative performance is related to graph use is that prolonged under-performance may result in non-visual disclosure without graphs, or, alternately, that fewer graphs are used in a year with lower performance.

As Figure 1 shows, photographs have been used in the annual reports since the 1950s. In the early stages, photographs were used to document events, key people and production facilities. Diagrams, 
meanwhile, were rarely used before the 1990s, and only became commonplace during the $2000 \mathrm{~s}$. The increase in graph use is also relatively recent. Prior to the 1980 s, only a small number of graph types had been used to demonstrate financial performance, typically of turnover, number of employees, share price (or dividends), or total assets. This study shows that, in line with previous research (e.g. Beattie and Jones, 1997), concrete graphs have increasingly been used to illustrate a wider range of financial measures, as well as non-financial information. A possible explanation for the surge in graph use is related to the changed structure of the report; after 1981, the reporting choice consisted of presenting business units separately, with graphs showing key performance indicators for each unit. In addition, from 1998 onwards, reports also featured conceptual graphs, e.g. market prognoses with predictions of considerable future growth (see the example in Table 1), and idea-based illustrations of the strategy. The frequency of conceptual graphs per year ranged from 0 percent (2006) to around 20 percent (2011) with a yearly average of around 8 percent between 1998 and 2016.

As for the visual style of representing the company's performance and identity, the front covers (serving as proxies for photographs) of the 1950s often depicted the main production facility in Sweden, an as-is representation of the main resource of a manufacturing-oriented company. The depictions of internal aspects like the production facilities and products gradually gave way to depictions of customers, abstract ideas and services in later years, and, although conceptual (generic or symbolic) visuals have been used intermittently since the 1960s, they became common after 1990, indicating a more symbolic approach in these reports. That the subject of representation has departed from company-specific and internal matters as the referent, to an external referent, and finally to a symbolic referent is evident in the progression of subjects depicted on the front pages. While early front pages showed factories (1950s), products (1960s), employees (1950s-1970s), and customers (1980s), these as-is depictions were supplanted by generic examples of people communicating (1990s2000s) and the company vision of "the networked society" (2010s) on the front page. Company specific as-is representations on the front covers were fully replaced by generic or symbolic visuals by 2005 . This indicates that reports increasingly reflect an abstract or imagined referent, rather than the concrete, material company, through a symbolic relationship between visual and referent.

The developments outlined above show that Ericsson has increasingly incorporated visuals that show what the corporation strives to become (symbolic photos, conceptual graphs, conceptual diagrams) rather than what it is or has been (as-is photos, concrete diagrams). The change in visuals use from using only concrete to also incorporating a mix of concrete and conceptual representations could be described as a changing balance between performance-based to idea-based visual messages. The shift can be understood using the perspective on visuals in annual reports discussed by Preston et al. (1996). They propose a view that the company as portrayed in annual reports simultaneously constructs and is constructed by the organizational reality. In the present case, this construction increasingly takes place away from the concrete goings-on in the company, becoming more a matter of portraying an image or idea in line with how the company wishes to be perceived and the strategy for how to achieve this, rather than showing what is perceived to be already there.

In relation to the company context, the representations of factories and products in the 1950s and 1960s can be linked to Ericsson introducing several innovative communication technologies to the market during this time, including switches and telephones. The practice of including close-up photographs of technology on the front page $(1968,1969,1970$ and 1972) can be seen as a way to convey the identity of a skilled telecom manufacturer by highlighting the quality and complexity of its products. The 1960s and 1970s saw rapid turnover growth, and the share capital was increased often to support expansion (Åsgård and Ellgren, 2000). The expansion stage, fueled by product innovations, could explain why the company frequently portrayed products (offering) and employees (innovators) 
on its front pages. By the 2000s, the focus on strategy and offering can be related to its increasing focus on offering services and systems as a service (Davies, 2004), and the company's offering was therefore no longer synonymous with a single employee or a product, but with the service system as a whole. For example, a photo of children waving to each other (2005), or a fisherman working on his laptop (2009) represents users of communication technology that Ericsson provides as generic examples without specifically linking the children or the fisherman to the company's offering. Furthermore, the symbolic representations of the networked society of the 2010s were in line with the strategy that the company developed in the late 2000s in response to the rapidly developing telecommunications industry. The new strategy of being an enabler of the networked society is clearly reflected in the front pages of the 2010s, where the relationship between representation and referent takes place on the conceptual level, with front covers showing a referent that is an idea rather than an as-is representation of a concrete reality.

\section{Diagrams in Ericsson's annual reports}

As indicated in Figure 1, photographs were initially the predominant visual format, but they were complemented by a higher number of graphs starting in the 1980s, and by diagrams in the 2000s. Although photographs have increased in nominal terms, diagrams and graphs are increasingly frequent relative to photographs based on the number of occurrences. This indicates a shift toward representing the company more with graphs and diagrams relative to photos, which underscores the importance of increasing the understanding of how diagrams serve as communicative resources in corporate reporting. An overview of diagrams in terms of the topics illustrated is presented in Table 2, which divides up the 171 diagrams used in Ericsson's annual reports by topic.

[TABLE 2]

As the table shows, strategy was the most frequently illustrated topic, with governance processes and structures coming a close second. Strategic diagrams such as company values, the business model, and company goals could be expected in an annual report, to fulfill the purpose of attracting investors by outlining future directions. In contrast, the number of governance-related diagrams rose in the 2000s, most likely as a result of the corporate governance report (a mandatory report for listed companies in Sweden) being included in Ericsson's main annual report in 2005. The corporate governance section should contain a detailed account of corporate governance principles and processes, and in Ericsson's case these are explained using multiple diagrams, including the risk management process, the board's yearly meeting cycle and the governance structure of the company.

With regard to which diagrams are used, a noteworthy observation is that, of 177 diagrams, only 89 unique diagrams were used. The 89 different diagrams were repeated in several reports with only slight variations in color or style. Offering and market descriptions had the highest share (around 80 percent) of unique diagrams, whereas diagrams in the governance and organizational structure category were often re-used in more than one report. This suggests that some diagram types (e.g. business models, service systems, and company values) serve as stable conceptual representations which remain the same over many years, while strategic diagrams illustrate information specific to a certain year (e.g. current market prospects). Repeated diagrams could be seen as having a similar communicative function to representations of a factory or employees, which are also enduring 
resources of the company, although employees and factories are more concrete referents than, e.g. the risk management process or the organizational structure.

Conceptual diagrams (e.g. strategy, governance and offering) are more common than concrete ones (the production location maps); however, this ratio has changed over time. At first, maps were common, with diagrams showing either production locations or sales agents. Such diagrams highlight the company's role as a global enterprise. Between 1949 and 1994, 24 concrete (maps) and only four conceptual diagrams were used; however, beginning in the 1990s, this ratio began to shift. After the first conceptual diagram use in 1996, only 8 concrete diagrams were used, compared to 141 conceptual diagrams in 1996-2016. While uses of conceptual diagrams in the 2000s were mostly confined to the corporate governance report, by the mid-2000s, diagrams were incorporated in the other narrative sections of the report as well, for instance to describe the company, its strategy, and its market prospects. This suggests that conceptual diagrams had become a common visualization type in the annual report as a whole. Seeing as the increase in diagram use is concurrent with the overall tendency to reference a conceptual rather than concrete referents, diagrams can be interpreted as a reflection, and perhaps a result of, a new visual communication style which is more strongly geared toward intangible values.

Following deregulations and the digitization of the telecom industry, Ericsson faced a new competitive environment around the turn of the millennium (Åsgård and Ellgren, 2000) and adapted to focus on a more service-based offering. The manufacturer logic was abandoned in favor of an integrated network supplier approach, and the offering changed from communication products, e.g. mobile switches and subsystem products, to value-added communication services on a network level (Davies, 2004). The shift from using concrete maps to conceptual diagrams coincides with Ericsson's strategic shift from manufacturer to service provider. In fact, the first use of a conceptual diagram was to highlight the difference between a manufacturing-oriented and a service-oriented value chain in 1996. Perhaps the decreasing focus on tangible aspects of the value chain to intangible ones is thus reflected in the gradual shift toward using conceptual diagrams to describe the company and its strategy.

\section{Conclusions}

This case-study of visuals use in annual reports finds that in Ericsson's reports, numerical and narrative accounting information is increasingly complemented by photographs, graphs and diagrams. Diagrams especially have become increasingly common in annual reports during the 2000s, but so far, this corporate communication practice has received limited attention from scholars. Thus, the primary contribution of this study is to describe the development of a hitherto neglected visual element by showing how diagrams are increasingly used to represent the company's actions, strategies and structures. The results corroborate previous findings that the annual report is becoming a more visual document in terms of the number of visual elements used (e.g. McKinstry, 1996; Beattie et al., 2008; Campbell et al., 2009; Ditlevsen, 2012b), but they also contribute additional knowledge about patterns in the visual communication style of the reports with an emphasis on the role of diagrams.

Specifically, by applying a semiotic framework of representative styles to Ericsson's annual reports, this study specifies the following three patterns with regard to visuals use in the annual report. First, while photographs, graphs and diagrams are used more frequently overall, the number of diagrams and graphs has increased relative to photos. Second, early visuals were primarily concrete representations showing tangible dimensions of the company, but an increasing share of diagrams, graphs and photographs are conceptual translations of the company and its performance that 
highlights intangible dimensions of the firm. Third, as photographs became less specific, diagrams were introduced to represent specific, internal matters such as the organizational structure, strategy and governance systems. By comparing the use of diagrams with photographs and graphs, the study finds evidence that diagrams seem to have taken over some of the functions previously carried out by photographs when it comes to describing the internal and external environment of the company, which is a conclusion not previously presented in reporting communication studies.

Explanations for the patterns outlined above were found to include both internal factors, e.g. poor performance resulting in fewer visuals and individual preferences resulting in specific visual styles, as well as external factors, e.g. legislation mandating a corporate governance report which coincided with more diagrams being used, and external market pressures shifting the offering from being productbased to being service-based. This transformation is evident in the telecom industry (Li and Whalley, 2002) as well as many other industries in light of new complex, technology ecosystems and business models (D'Souza et al., 2015), where companies are increasingly operating as open systems with large networks rather than closed entities. Another possible explanation for the surge in generic representations could be that companies are increasingly expected to provide information about themselves to outside stakeholders (Evangelisti Allori and Garzone, 2011), whereby communication with easily understandable visuals can become a way to increase the company's legitimacy among the audience. This is in line with previous studies proposing that reporting behavior is normalized over time (Beattie et al., 2008) and that companies frequently reference the same themes, e.g. globalization (Preston and Young, 2000). Symbols that become generic industry standards may be less apt to convey a company-specific reality and more a standardized way to ensure that the company is perceived as legitimate (cf. Dowling and Pfeffer, 1975). From this perspective, the increasing use of generic visuals can be seen as a form of conformity to social norms of reporting to improve legitimacy. For companies, a downside to adopting similar symbolism is an increasing visual similarity across companies' corporate disclosure, something which Guthey and Jackson (2005) refer to as an authenticity paradox.

A situation where a shift in representative styles was particularly observable was in Ericsson's approach to reporting in times of poor performance. There is a difference in the response to lower financial performance in the early 2000s, where the approach was minimal non-visual disclosure, and the decrease in performance in 2016, when the level of visuals use remained high except for fewer graphs being used. The two identified approaches to report performance (minimal and selective visuals use), especially the potential shift from one to the other as a result of the shift to the conceptual visual communication style based on intangible dimensions, could be worth confirming in large-sample studies, as per Penrose's (2008) call for more research on graph use under different performance levels.

A limitation of the present study is that I investigate a single company's annual reports to examine changes in diagram use. Although this allowed for an in-depth study of the context and diagram use and the links to the overall visual communication style, the single-case design can only hint at more general trends of visual communication in annual reports. Future studies could investigate these patterns on a larger scale to determine whether the trend of depicting corporations with a higher ratio of graphs and diagrams relative to photographs is general, or is specific to conditions such as country, industry and company size. For instance, it could be fruitful to examine if there are differences between preferred diagrams in different industries, as this study found that Ericsson's shift from a manufacturing to a service logic coincided with Ericsson using more conceptual diagrams, which indicates that the characteristics of an industry and offering may be reflected in the choice of diagram types in the annual report. 


\section{References}

Abdul Rahman, A., Hamdan, M.D. and Ibrahim, M.A. (2014), "The use of graphs in Malaysian companies' corporate reports: a longitudinal study", Procedia - Social and Behavioral Sciences,

Anderson, C.J. and Imperia, G. (1992), "The corporate annual report: a photo analysis of male and female portrayals", The Journal of Business Communication, Vol. 29 No. 2, pp. 113-129.

Åsgård, L. and Ellgren, C. (2000), Historien om Ericsson, Nordstedts Förlag, Stockholm.

Bartlett, S. and Jones, M.J. (1997), "Annual reporting disclosures 1970-90: an exemplification", Accounting, Business \& Financial History, Vol. 7 No. 1, pp. 61-80.

Beattie, V. and Jones, M.J. (1997), "A comparative study of the use of financial graphs in the corporate annual reports of major US and UK companies", Journal of International Financial Management \& Accounting, Vol. 8 No. 1, pp. 33-68.

Beattie, V., Dhanani, A. and Jones, M.J. (2008), "Investigating presentational change in UK. Annual reports: a longitudinal perspective", Journal of Business Communication, Vol. 45 No. 2, pp. 181222.

Branco, M.C. and Rodrigues, L.L. (2006), "Communication of corporate social responsibility by Portuguese banks: a legitimacy theory perspective", Corporate Communications: An International Journal, Vol. 11 No. 3, pp. 232-248.

Campbell, D. and Abdul Rahman, M.R. (2010), "A longitudinal examination of intellectual capital reporting in Marks \& Spencer annual reports, 1978-2008", The British Accounting Review, Vol. 42 No. 1, pp. 56-70.

Campbell, D., McPhail, K. and Slack, R. (2009), "Face work in annual reports: a study of the management of encounter through annual reports, informed by Levinas and Bauman", Accounting, Auditing \& Accountability Journal, Vol. 22 No. 6, pp. 907-932.

Courtis, J.K. (1997), "Corporate annual report graphical communication in Hong Kong: effective or misleading?", Journal of Business Communication, Vol. 34 No. 3, pp. 269-288.

D'Souza, A., Wortmann, H., Huitema, G.B. and Velthuijsen, H. (2015), "A business model design framework for viability: a business ecosystem approach", Journal of Business Models, Vol. 3 No. 2, pp. 1-28.

David, C. (2001), "Mythmaking in annual reports", Journal of Business and Technical Communication, Vol. 15 No. 2, pp. 195-222.

Davies, A. (2004), "Moving base into high-value integrated solutions: a value stream approach", Industrial and Corporate Change, Vol. 13 No. 5, pp. 727-756.

Davison, J. (2010), "[In]visible [in]tangibles: visual portraits of the business élite", Accounting, Organizations and Society, Vol. 35 No. 2, pp. 165-183.

Davison, J. (2014), "Visual rhetoric and capital", Accounting, Organizations and Society, Vol. 39 No. 1, pp. 20-37.

Davison, J. (2015), "Visualising accounting: an interdisciplinary review and synthesis", Accounting and Business Research, Vol. 45 No. 2, pp. 121-165.

De Groot, E., Nickerson, C., Korzilius, H. and Gerritsen, M. (2015), "Picture this: developing a model for the analysis of visual metadiscourse", Journal of Business and Technical Communication, pp. 1-37.

Ditlevsen, M.G. (2012a), "Revealing corporate identities in annual reports", Corporate Communications: An International Journal, Vol. 17 No. 3, pp. 379-403.

Ditlevsen, M.G. (2012b), “Telling the story of Danisco's annual reports (1935 through 2007-2008) from a communicative perspective", Journal of Business and Technical Communication, Vol. 26 No. 1, pp. 92-115. 
Dougherty, D.J. and Kunda, G. (1990), "Photograph analysis: a method to capture organizational belief systems", in Gagliardi, P. (Ed.), Symbols and Artifacts: Views of the Corporate Landscape, Aldine de Gruyter, New York, NY.

Dowling, J. and Pfeffer, J. (1975), "Organizational Legitimacy: social values and organizational behavior", The Pacific Sociological Review, Vol. 18 No. 1, pp. 122-136.

Ehrenkrona, M. (1998), Passion för teknik: Om drivkrafter inom Ericsson Radio Access AB, Ekerlids Förlag, Stockholm.

Evangelisti Allori, P. and Garzone, G. (2011), "Discourse, identities and genres in corporate communication: an introduction", in Evangelisti Allori, P. (Ed.), Discourse, Identities and Genres, in Peter Lang AG, Internationaler Verlag der Wissenschaften, pp. 9-26.

Falk, T., Petri, C.-J., Roy, J. and Walldius, Å. (2016), "Illustrating an organization's strategy as a map", in Nilsson, F., Petri, C.-J. and Westelius, A. (Eds), Strategic Management Control, Studentlitteratur, Lund, pp. 27-66.

Guthey, E. and Jackson, B. (2005), "CEO portraits and the authenticity paradox", Journal of Management Studies, Vol. 42 No. 5, pp. 1057-1082.

Heiser, J. and Tversky, B. (2006), "Arrows in comprehending and producing mechanical diagrams", Cognitive Science, Vol. 30, pp. 581-592.

Husin, N.M., Cooper, K. and Olesen, K. (2012), "Analysis of intellectual capital disclosure - an illustrative example", Journal of Intellectual Capital, Vol. 13 No. 2, pp. 196-220.

Karreman, J., De Jong, M. and Hofmans, S. (2014), "The effects of different parts of the annual report on potential investors' attitudes towards the company and on the corporate reputation", IEEE Transactions on Professional Communication, Vol. 57 No. 2, pp. 78-97.

Kazmierczak, E.T. (2001), "A semiotic perspective on aesthetic preference, visual literacy, and information design", Information Design Journal, Vol. 10 No. 2, pp. 176-187.

Kress, G. and van Leeuwen, T. (2006), Reading Images: The Grammar of Visual Design, 2nd ed., Routledge, London \& New York, NY.

Larkin, J.H. and Simon, H.A. (1987), "Why a diagram is (sometimes) worth ten thousand words", Cognitive Science, Vol. 99, pp. 65-99.

$\mathrm{Li}, \mathrm{F}$. and Whalley, J. (2002), "Deconstruction of the telecommunications industry: from value chains to value networks", Telecommunications Policy, Vol. 26, pp. 451-472.

McKinstry, S. (1996), "Designing the annual reports of Burton PLC from 1930 to 1994", Accounting, Organizations and Society, Vol. 21 No. 1, pp. 89-111.

Meirelles, I. (2013), Design for Information, Rockport Publishers.

Mouritsen, J., Larsen, H.T. and Bukh, P.N. (2001), "Intellectual capital and the "capable firm": narrating, visualising and numbering for managing knowledge", Accounting, Organizations and Society, Vol. 26, pp. 735-762.

Penrose, J.M. (2008), "Annual report graphic use: a review of the literature", Journal of Business Communication, Vol. 45 No. 2, pp. 158-180.

Preston, A.M. and Young, J.J. (2000), "Constructing the global corporation and corporate constructions of the global: a picture essay", Accounting, Organizations and Society, Vol. 25, pp. 427-449.

Preston, A.M., Wright, C. and Young, J.J. (1996), "Imag[in]ing annual reports", Accounting, Organizations and Society, Vol. 21 No. 1, pp. 113-137.

Tversky, B. (1997), “Cognitive principles of graphic displays”, Technical Report FS-97-03, AAAl, pp. 116124. 
TABLE 1

Roles of visual elements in annual reports. The examples of diagrams and graphs come from Ericsson's annual reports (used with permission from Telefonaktiebolaget LM Ericsson's archive with the Centre For Business History, www.naringslivshistoria.se).

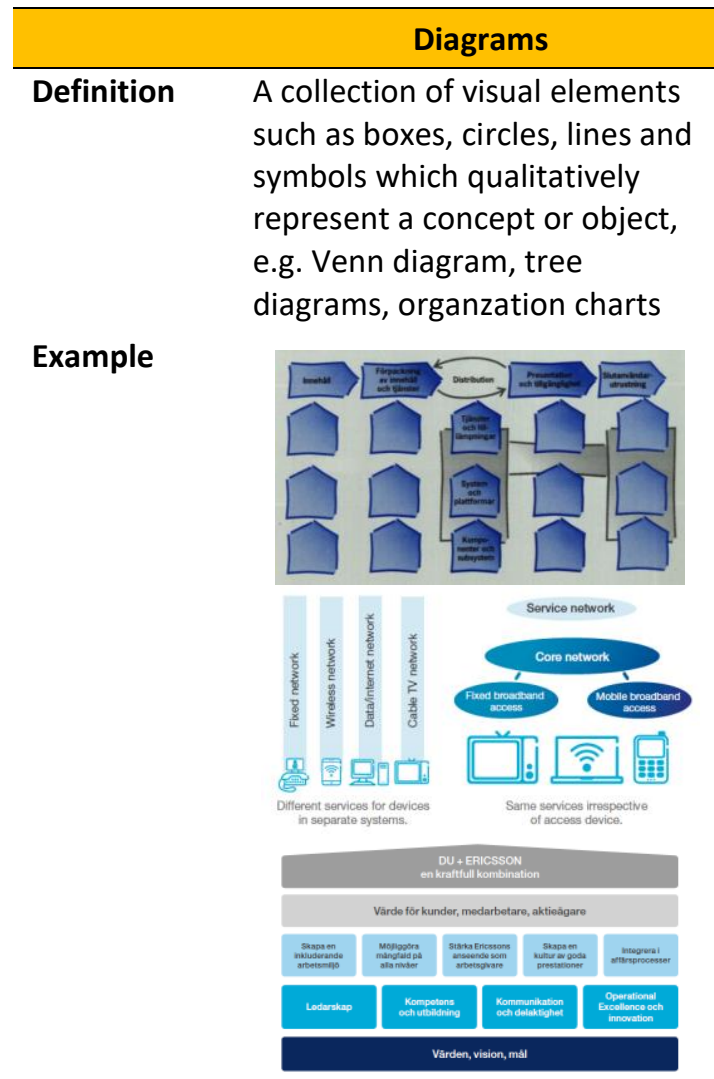

Value chain (1996), Network transformation (2010), Diversity strategy (2015)

Information Relationships between concepts visualized (static or dynamic)

\section{Concrete referent}

\section{Conceptual referent}

Terrain (bounded by physical aspects) that exists, with reality mapped accordingly; e.g. terrain, location, mechanical function

Ideas (bounded by conceptual aspects); e.g. processes, strategic logics, ideas, values, organization structure, business model, transformation, cause and effect

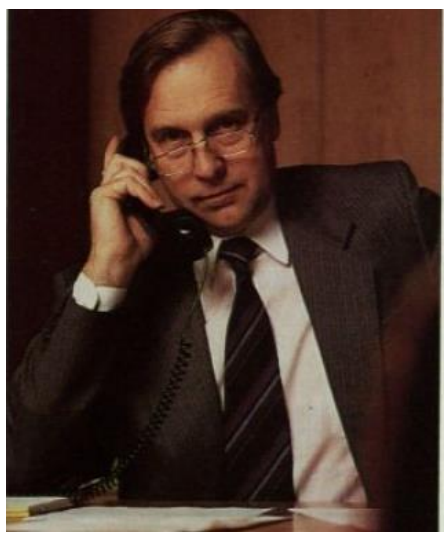

Situations, people, locations; related to the organization through different relationships between referent and representation

Photo as as-is representation: CEO, actual board members, factories, products, employees, customers, depicting past and current realities. Can show internal or external as-is representations.

Photo as generic example: A customer, an employee, a factory; exemplifying a current or future reality (the idea of having customers).

Photo as symbolic: Showing the identity by depicting a current or future state.

\section{Graphs}

A collecton of visual elements corresponding in size, placement or shape to a quantitative amount. Also referred to as charts, e.g. bar charts, pie charts, line charts

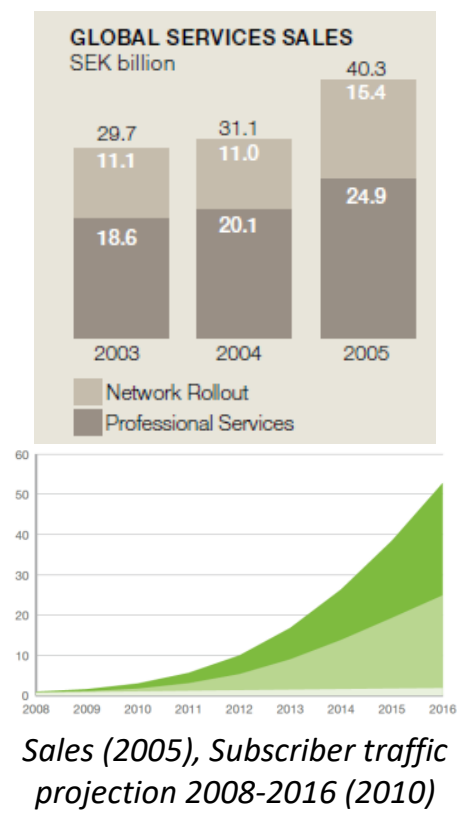

Numerical data related to the organization, either past or projected numbers, e.g. financial measures (earnings, profit, share price) or nonfinancial (e.g. employees).

Past performances and the current standings

Future performance and standings (e.g. prognoses) 
TABLE 2

Diagram topics and prevalence of types in Ericsson's annual reports

\begin{tabular}{llcc}
\hline Diagram topic & Example of concepts illustrated & $\begin{array}{c}\text { Total number } \\
\text { of diagrams }\end{array}$ & $\begin{array}{c}\text { Share of } \\
\text { total no. (\%) }\end{array}$ \\
\hline Strategy & $\begin{array}{l}\text { Our values, company goals, business model, } \\
\text { strategy frontier }\end{array}$ & 43 & 24.3 \\
$\begin{array}{l}\text { Governance processes } \\
\text { and structures }\end{array}$ & $\begin{array}{l}\text { Ericsson Group Management System, Board } \\
\text { yearly cycle, Strategy yearly cycle, Risk } \\
\text { management process }\end{array}$ & 39 & 22.0 \\
Production locations & Map of production locations or network & 27 & 15.3 \\
Offering & Service process diagrams, product components & 20 & 11.3 \\
Organizational structure & An org chart, org tree (of decision making) & 25 & 14.1 \\
Market prognosis & $\begin{array}{l}\text { The evolution of mobile systems, network } \\
\text { convergence, Industry actor roles matrix }\end{array}$ & 21 & 11.9 \\
Stakeholders & & 2 & 1.1 \\
\hline All categories & & $\mathbf{1 7 7}$ & $\mathbf{1 0 0}$ \\
\hline
\end{tabular}

\section{FIGURE 1}

Types of visual elements used in Ericsson's annual reports 1947-2016

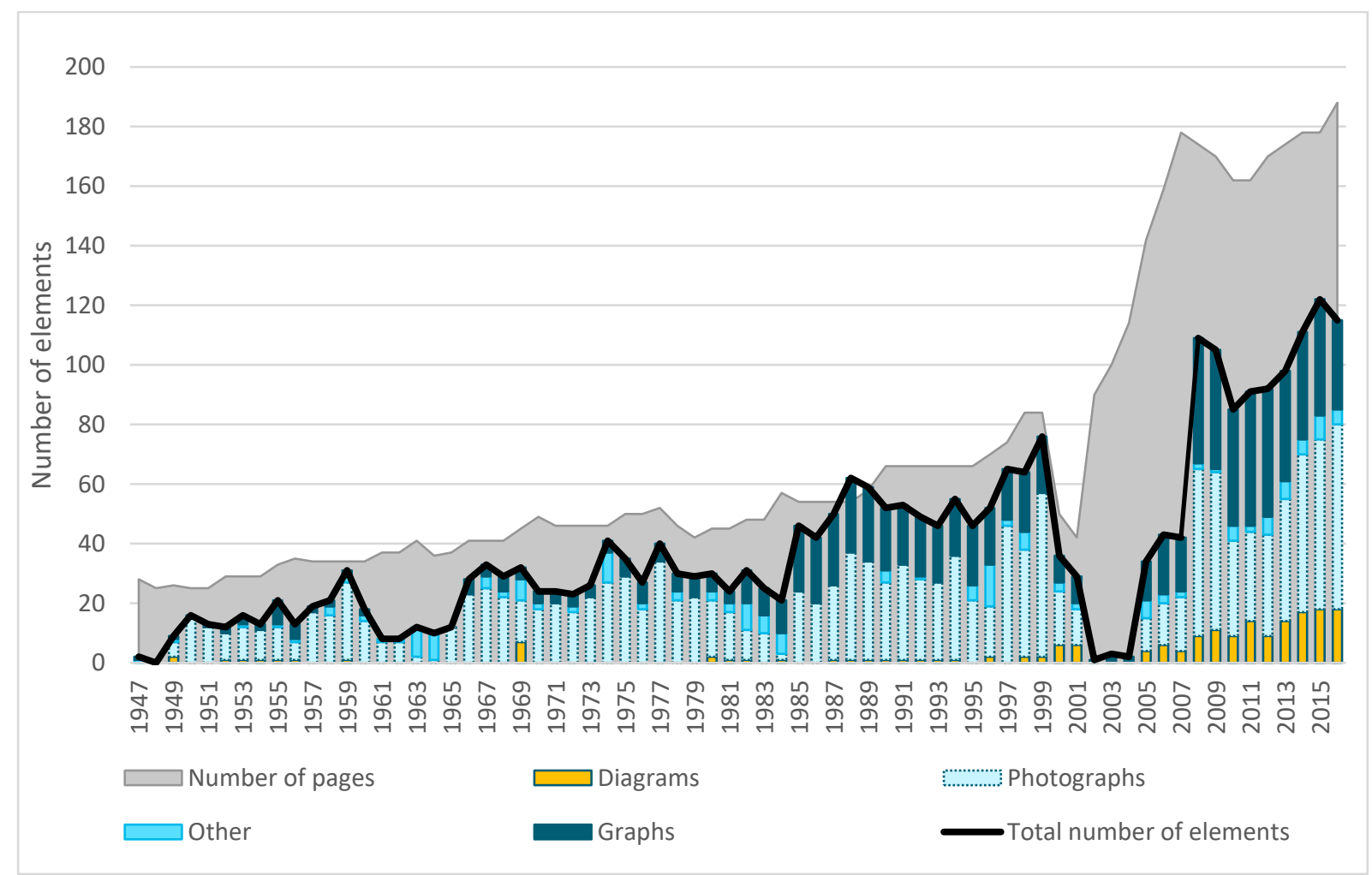

